\title{
Risks of pregnancy and birth in obese primiparous women: an analysis of German perinatal statistics
}

\author{
Volker Briese • Manfred Voigt • Josef Wisser • \\ Ulrike Borchardt $\cdot$ Sebastian Straube
}

Received: 3 April 2009/Accepted: 24 December 2009/Published online: 23 January 2010

(C) The Author(s) 2010. This article is published with open access at Springerlink.com

\begin{abstract}
Purpose To compare risks of pregnancy and birth in obese (body mass index, $\mathrm{BMI} \geq 30$ ) and normal weight women (BMI 18.5-24.99) giving birth to their first child. Methods We analysed data of 243,571 pregnancies in primiparous women from the German perinatal statistics of 1998-2000. We calculated odds ratios (ORs) with 95\% confidence intervals (CIs) for selected pregnancy and birth risks. ORs were adjusted for the confounding factors age, smoking status, single mother status, and maternal education.

Results Obesity during pregnancy is common in primiparous women ( $n=19,130 ; 7.9 \%$ of all cases) and it is significantly associated with a number of risks of pregnancy and birth, including diabetes [OR 3.71 (95\% CI 2.93; 4.71);
\end{abstract}

V. Briese

Department of Obstetrics and Gynaecology,

University of Rostock, Rostock, Germany

M. Voigt

Institute for Perinatal Auxology,

Klinikum Südstadt, Rostock, Germany

J. Wisser $(\bowtie)$

Department of Obstetrics and Gynaecology,

University Hospital Zurich, Frauenklinikstrasse 10,

Zurich 8091, Switzerland

e-mail: josef.wisser@usz.ch

U. Borchardt

Research Institute for the Biology of Farm Animals (FBN),

Research Unit Genetics and Biometry,

Dummerstorf, Germany

S. Straube

Department of Occupational and Social Medicine,

University of Göttingen, Göttingen, Germany $p<0.001$ ], hypertension [OR 8.44 (7.91; 9.00); $p<0.001$, preecalmpsia/eclampsia [OR $6.72 \quad(6.30 ; 7.17) ; p<$ $0.001]$, intraamniotic infection [OR $2.33(2.05 ; 2.64)$; $p<0.001$ ], birth weight $\geq 4,000$ g [OR $2.16(2.05 ; 2.28)$; $p<0.001$ ], and an increased rate of Caesarean section [OR $2.23(2.15 ; 2.30) ; p<0.001]$. Some risks were less frequent in the obese such as cervical incompetence [OR $0.55(0.48$; $0.63) ; p<0.001$ ] and preterm labour [OR $0.47(0.43 ; 0.51)$; $p<0.001]$.

Conclusions Obesity during pregnancy is an important clinical problem in primiparous women because it is common and it is associated with a number of risks of pregnancy and birth. Because of these increased risks, obese women need special attention clinically during the course of their first pregnancy. Weight reduction before the first pregnancy is generally indicated in obese women to prevent the above-mentioned complications of pregnancy and birth.

Keywords Body mass index - Parity - Diabetes . Hypertension · Preeclampsia

\section{Introduction}

Obesity is common among women of childbearing age. Recent estimates of the prevalence of obesity in adults approach a quarter of the population [1,2]. Some other work puts the prevalence of obesity in pregnancy at about $10-11 \%[3,4]$.

The consequences of obesity in pregnancy include a number of adverse outcomes for mother and child. A large retrospective cohort study from UK found that gestational diabetes, preeclampsia, delivery by emergency Caesarean section, postpartum haemorrhage, urinary tract infection, 
wound infection, birth weight above the 90th centile, and intrauterine death were more common in the obese [3]. An analysis of German perinatal statistics demonstrated higher rates of hypertension, preeclampsia, gestational diabetes, Caesarean section, fetal macrosomia, fetal structural anomalies, and low neonatal Apgar score for obese compared to normal weight women $[4,5]$. The adverse health effects of maternal obesity extend beyond pregnancy. In women as in men, obesity is a risk factor for the development of hypertension, diabetes, and dyslipidaemia. Maternal obesity also influences offspring outcomes well beyond the neonatal period. For example, a recent study observed a correlation between obesity in 9-year-olds and maternal pregestational weight [6].

Perinatal outcomes are often influenced by parity and for this reason we wanted to examine the effects of obesity in pregnancy separately for women who experience their first pregnancy. In this study, we therefore set out to analyse the prevalence of pregnancy and birth risks in obese primiparous women compared to primiparous women of normal weight based on a large set of data from German perinatal statistics.

\section{Materials and methods}

Data for this study were taken from the German perinatal statistics of 1998-2000. Collection of perinatal statistics is mandatory in Germany. The German federal states Bavaria, Brandenburg, Hamburg, Mecklenburg-Western Pomerania, Lower Saxony, Saxony, Saxony-Anhalt, and Thuringia contributed data. Our database contains 508,926 datasets from singleton pregnancies in total. Among these were 243,571 datasets from primiparous women, i.e. data collected during the first pregnancy. These data formed the basis of the present analysis.

By convention, obesity was defined by a body mass index (BMI) $\geq 30$ and normal weight by a BMI between 18.5 and 24.99. We compared obese primiparae to normal weight primiparae with regard to the following pregnancy risks that are coded for in German perinatal statistics: coagulopathies, diabetes mellitus (known before pregnancy), small stature, previous infertility treatment, hypertension, proteinuria $(>1 \%$ ) , moderate to severe edema, gestational diabetes, cervical incompetence, preterm labour, anaemia, hypotension. Furthermore, we investigated these birth risks: premature rupture of membranes, postterm birth, in utero fetal demise, preterm birth, preeclampsia/eclampsia, intraamniotic infection, pyrexia during delivery, occurrence of an abnormal cardiotocogram (CTG) or concerning fetal heart sounds, occurrence of green amniotic fluid, occurrence of fetal acidosis during delivery (as evidenced by fetal blood sampling), prolonged first stage of labour, prolonged second stage of labour, cephalopelvic disproportion, transverse presentation, high fetal head station, birth weight $\geq 4,000 \mathrm{~g}$, and the rate of Caesarean sections.

Nominal data are expressed as percent values. For bivariate analyses the chi-squared test was used. Multivariable logistic regression models were used to assess the association between risks of pregnancy or birth and BMI. The models were adjusted for age, smoking status, single mother status, and maternal education. Age was categorised into three groups: $\leq 22,23-31$, and $\geq 32$ years. Smoking status was categorised into non-smokers, smokers consuming $\leq 10$ cigarettes/day, and smokers consuming $\geq 11$ cigarettes/day. Regarding maternal education, women were either "without qualification", i.e. classified as "unskilled labourers" in German perinatal statistics or were "others" when they were given an occupational classification other than "unskilled labourer". Odds ratios (ORs) with $95 \%$ confidence intervals (CIs) were calculated. A value of $p<0.05$ was considered statistically significant. All statistical analyse were performed with SPSS software, version 15.0 .

\section{Results}

Figure 1 shows the distribution of BMI among primiparous women. Of all cases, $68.4 \%$ were of normal weight $(n=166,675)$ and $7.9 \%$ were obese $(n=19,130)$. The analyses described below are a comparison between these two groups. Table 1 summarises some characteristics of the two groups that we expected to be confounding factors. It can be seen that obese and normal weight primiparae differed significantly with regard to age, smoking status, single mother status, and maternal education. Because these parameters can also be expected to influence the prevalences of the pregnancy and birth risks that form the focus of this study, it was necessary to adjust for these as confounding factors in our analyses.

Table 2 illustrates some risks of pregnancy coded for in German perinatal statistics. From the adjusted OR, it is apparent that obese primiparous women have higher odds of coagulopathies, diabetes, hypertension, proteinuria, and edema but lower odds of cervical incompetence, preterm labour, anaemia, and hypotension. In all cases the differences were statistically highly significant $(p<0.001)$. The highest odds increases associated with obesity could be observed for hypertension (adjusted OR 8.44), moderate to severe edema (adjusted OR 6.11), gestational diabetes (adjusted OR 4.55), proteinuria (adjusted OR 4.41), and diabetes known before pregnancy (adjusted OR 3.71). 


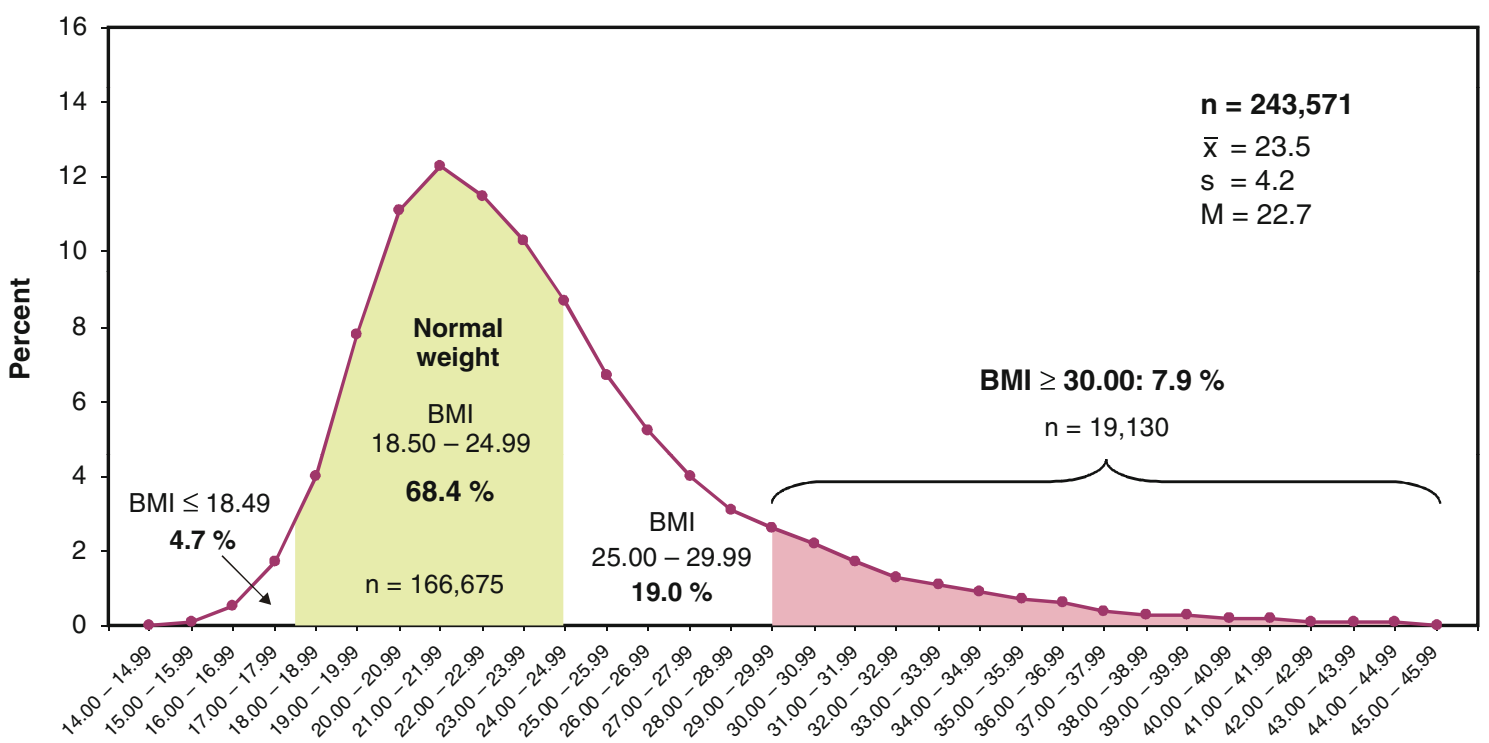

Body mass index $\left(\mathrm{kg} / \mathrm{m}^{2}\right)$

Fig. 1 Distribution of BMI in the study population

Table 1 Characteristics of the study population

\begin{tabular}{llll}
\hline Parameter & $\begin{array}{l}\text { Normal weight } \\
\text { (BMI 18.50-24.99) }\end{array}$ & $\begin{array}{l}\text { Obesity } \\
(\text { BMI } \geq 30.00)\end{array}$ & $\begin{array}{l}p \text { (chi- } \\
\text { squared } \\
\text { test) }\end{array}$ \\
\hline $\begin{array}{l}\text { Age (years) } \\
\quad \leq 22\end{array}$ & 20.5 & 19.2 & $<0.001$ \\
$23-31$ & 61.9 & 64.0 & \\
$\quad \geq 32$ & 17.6 & 16.8 & \\
Smoking status & & & $<0.001$ \\
$\quad$ Non-smokers & 85.6 & 81.2 & \\
$\quad$ Smokers: $\leq 10$ cig./day & 11.4 & 13.6 & \\
$\quad$ Smokers: $\geq 11$ cig./day & 3.0 & 5.2 & $<0.001$ \\
Single mother & & & \\
$\quad$ Yes & 18.5 & 16.7 & $<0.001$ \\
$\quad$ No & 81.5 & 83.3 & \\
Education & & & \\
$\quad$ Without qualification & 5.6 & 8.2 & \\
$\quad$ classified as "unskilled & & & \\
$\quad$ labourer") & & 91.8 & \\
$\quad$ Others & 94.4 & &
\end{tabular}

Table 3 compares the prevalences of birth risks between obese and normal weight primiparae. With the exception of a prolonged second stage of labour, all investigated birth risks were significantly more common in the obese; and except for in utero fetal demise the level of significance was always high $(p<0.001)$. The odds increases were highest for preeclampsia/eclampsia (adjusted OR 6.72), cephalopelvic disproportion (adjusted OR 2.41), and intraamniotic infection (adjusted OR 2.33). Neonates with high birth weight (adjusted OR 2.16) and Caesarean sections (adjusted OR 2.23) were also more than twice as
Table 2 ORs for pregnancy risks in obese compared to normal weight primiparous women

\begin{tabular}{ll}
\hline Pregnancy risks & OR $(95 \% \mathrm{CI})^{\mathrm{a}}$ \\
\hline Coagulopathies & $1.68(1.45 ; 1.95)^{*}$ \\
Diabetes mellitus & $3.71(2.93 ; 4.71)^{*}$ \\
Small stature & $1.71(1.32 ; 2.21)^{*}$ \\
Previous infertility treatment & $1.83(1.69 ; 1.99)^{*}$ \\
Hypertension & $8.44(7.91 ; 9.00)^{*}$ \\
Proteinuria $>1 \%$ o & $4.41(4.00 ; 4.99)^{*}$ \\
Edema & $6.11(5.68 ; 6.58)^{*}$ \\
Gestational diabetes & $4.55(3.94 ; 5.26)^{*}$ \\
Cervical incompetence & $0.55(0.48 ; 0.63)^{*}$ \\
Preterm labour & $0.47(0.43 ; 0.51)^{*}$ \\
Anaemia & $0.68(0.57 ; 0.80)^{*}$ \\
Hypotension & $0.25(0.16 ; 0.39)^{*}$ \\
\hline$* p<0.001$ & \\
${ }^{a}$ OR adjusted for the following parameters: age, smoking status, \\
single mother status, and education
\end{tabular}

likely in obese women. A steep increase in the rate of Caesarean sections (45.7\%) was observed in obese women older than 32 years (data not shown).

\section{Discussion}

The present study demonstrates that obesity during pregnancy is common in primiparous women and that it is associated with a number of risks of pregnancy and birth, including diabetes, hypertension, preecalmpsia, 
Table 3 ORs for birth risks in obese compared to normal weight primiparous women

\begin{tabular}{ll}
\hline Birth risks & OR $(95 \% \mathrm{CI})^{\mathrm{a}}$ \\
\hline Premature rupture of membranes & $1.19(1.14 ; 1.24)^{* *}$ \\
Postterm birth & $1.45(1.38 ; 1.52)^{* *}$ \\
In utero fetal demise (IUFD) & $1.25(1.02 ; 1.52)^{*}$ \\
Preterm birth & $1.14(1.06 ; 1.23)^{* *}$ \\
Preeclampsia/eclampsia & $6.72(6.30 ; 7.17)^{* *}$ \\
Intraamniotic infection & $2.33(2.05 ; 2.64)^{* *}$ \\
Pyrexia during delivery & $1.74(1.46 ; 2.07)^{* *}$ \\
Fetal distress & \\
$\quad$ Abnormal CTG & $1.38(1.32 ; 1.44)^{* *}$ \\
$\quad$ Green amniotic fluid & $1.64(1.55 ; 1.73)^{* *}$ \\
$\quad$ Fetal acidosis during delivery & $1.87(1.45 ; 2.41)^{* *}$ \\
Prolongated first stage of labour & $1.94(1.83 ; 2.01)^{* *}$ \\
Prolongated second stage of labour & $1.02(0.96 ; 1.07)$ \\
Cephalopelvic disproportion & $2.41(2.24 ; 2.59)^{* *}$ \\
Transverse presentation & $1.78(1.24 ; 2.55)^{* *}$ \\
High fetal head station & $1.75(1.54 ; 1.99)^{* *}$ \\
Birth weight $(\geq 4,000 \mathrm{~g})$ & $2.16(2.05 ; 2.28)^{* *}$ \\
Caesarean section rate & $2.23(2.15 ; 2.30)^{* *}$ \\
\hline
\end{tabular}

$* p<0.05 ; * * p<0.001$

OR adjusted for the following parameters: age, smoking status, single mother status, and education

intraamniotic infection, fetal macrosomia, and an increased rate of Caesarean sections. This work builds on previous analyses of German perinatal statistics but for the first time focuses on obese primiparous women and analyses pregnancy and birth risks associated with obesity in this group of patients.

Our results are in agreement with other work on pregnancy and birth risks among women who deliver their first child. A study from UK of 1,858 obese and 14,076 normal weight women found that preecalmpsia (adjusted OR 3.1), gestational hypertension (adjusted OR 2.2), emergency Caesarean section (adjusted OR 2.0), preterm delivery at less than 33 weeks of gestation (adjusted OR 2.0), and birth weight $>4,000 \mathrm{~g}$ (adjusted OR 1.9) were significantly more common in the obese [7]. A retrospective cohort study from Scotland demonstrated that the risk of elective preterm delivery increased with increasing BMI, while the risk of spontaneous preterm labour decreased [8]. This is in agreement with the lower risk of preterm labour found in obese women in the present study. In several other studies, rates of Caesarean section were increased in obese women [9-11]. Women, who are overweight or obese before pregnancy, have an increased risk of Caesarean section, particularly if they are also short [12].

The association between maternal obesity and delivery by Caesarean section is also confirmed after controlling for possible confounders in other recent retrospective and prospective analyses that were not restricted to primiparous women [13, 14].

There are some limitations to our study. For our statistical analysis, we used patient self-reporting of smoking status, single mother status, and maternal education. We have no way of verifying this information. Regarding smoking, a description of smoking status according to pregnancy trimester was not possible with our data. There is evidence that smoking has different effects at different times during the pregnancy [15]. The decision when a certain risk factor or disease was present in a given case was made by the obstetrician who filled in the data collection form (standard data collection form used in German perinatal statistics, "Perinatologischer Basis-Erhebungbogen"). The terms used in this form to describe pregnancy and birth risks may possibly be applied differently by different clinicians. We do not think that this is a significant limitation; however, because in most instances, the terms used in the data collection form are unambiguous.

Despite these limitations and predominantly due to the large number of cases included and the rigorous statistical analysis performed, we were able to provide a detailed description of pregnancy and birth risks in obese compared to normal weight primiparous women.

In conclusion, obesity during pregnancy is an important clinical problem in primiparous women because it is common and it is associated with a number of risks of pregnancy and birth. Because of these risks obese women need special attention clinically during the course of their first pregnancy. It follows that weight reduction before the first pregnancy is generally indicated in obese women as a preventive measure.

Conflict of interest statement We declare that we have no conflicts of interest.

Open Access This article is distributed under the terms of the Creative Commons Attribution Noncommercial License which permits any noncommercial use, distribution, and reproduction in any medium, provided the original author(s) and source are credited.

\section{References}

1. Hauner H, Bramlage $P$, Lösch C et al (2008) Prevalence of obesity in primary care using different anthropometric measuresresults of the German Metabolic and Cardiovascular Risk Project (GEMCAS). BMC Public Health 8:282

2. Vahratian A (2009) Prevalence of overweight and obesity among women of childbearing age: results from the 2002 National Survey of Family Growth. Matern Child Health J 13:268-273

3. Sebire NJ, Jolly M, Harris JP (2001) Maternal obesity and pregnancy outcome: a study of 287, 213 pregnancies in London. Int J Obes Relat Metab Disord 25:1175-1182

4. Voigt M, Straube S, Zygmunt M et al (2008) Obesity and pregnancy-a risk profile. Z Geburtshilfe Neonatol 212:201-205 
5. Voigt M, Zygmunt M, Henrich W et al (2008) Analysis of subgroup of pregnant women in Germany. 16th communication: morbid obesity: pregnancy risks, birth risks and status of the newborn. Geburtsh Frauenheilk 68:794-800

6. Gale CR, Javaid MK, Robinson SM et al (2007) Maternal size in pregnancy and body composition in children. J Clin Endocr Metab 92:3904-3911

7. Bhattacharya S, Campbell DM, Liston WA et al (2007) Effect of body mass index on pregnancy outcomes in nulliparous women delivering singleton babies. BMC Public Health 7:168176

8. Smith GC, Shah I, Pell JP et al (2007) Maternal obesity in early pregnancy and risk of spontaneous and elective preterm deliveries: a retrospective cohort study. Am J Public Health 97:157162

9. Dietz PM, Callaghan WM, Morrow B et al (2005) Populationbased assessment of the risk of primary cesarean delivery due to excess prepregnancy weight among nulliparous women delivering term infants. Matern Child Health J 9:237-244
10. Vahratian A, Siega-Riz AM, Savitz DA et al (2005) Maternal prepregancy overweight and obesity and the risk of caesarean delivery in nulliparous women. Ann Epidemiol 15:467-474

11. Weiss JL, Malone FD, Emig D et al (2004) Obesity, obstetric complications and cesarean delivery rate-a population-based screening study. Am J Obstet Gynec 190:1091-1097

12. Dempsey JC, Ashiny Z, Qiu CF et al (2005) Maternal pre-pregnancy overweight status and obesity as risk factors for cesarean delivery. J Matern Fetal Neonatal Med 17:179-185

13. Sheiner E, Levy A, Menes TS et al (2004) Maternal obesity as an independent risk factor for caesarean delivery. Paediatr Perinat Epidemiol 18:196-201

14. Burstein E, Levy A, Mazor M et al (2008) Pregnancy outcome among obese women: a prospective study. Am J Perinatol 25:561-566

15. Jaddoe VW, Troe EJ, Hofman A et al (2008) Active and passive maternal smoking during pregnancy and the risks of low birthweight and preterm birth: the Generation R Study. Paediatr Perinat Epidemiol 22:162-171 